\title{
PROYECTO ANDINO DE ESTUDIOS ARQUEOLÓGICOS (PEA). ZONA II, ANCASH INFORME PRELIMINAR DE EXPLORACIONES Hernán Amat Olazábal
}

Los problemas del desarrollo y las interrelaciones entre los focos culturales más importantes del periodo Formativo de los Andes Centrales ${ }^{1}$, con sus respectivas regiones conformadas por la costa, sierra y selva, han merecido, en la última década, una atención especial de parte de los arqueólogos tanto nacionales como extranjeros. Este interés, cada vez más creciente, se traduce en la estructuración de numerosos programas de investigación de campo y de gabinete. Tales son las expediciones realizadas por el Universidad de Tokio en el departamento de Huanuco y valles de la Costa Norte; la expedición arqueológica de la Universidad de Illinois que orientó sus investigaciones en la selva de Yarinacochas (Pucallpa); el programa recientemente iniciado por el Dr. McNeish en la sub-área del asierra central, etc.

Como estos mismos fines y en proyecciones más amplias surgió el PAEA. En reuniones

\footnotetext{
1 La Super Área Andina se ha dividido en tres áreas. El Área Central Andina que comprende el actual territorio del Perú, limitándola Piura por el Note y el valle de Ocoña por el Sur. El Área Meridional Andina comprende la Altiplanicie del Collao (Perú y Bolivia, el norte y centro chilenos y la zona Velliserrana del mismo país). El Área Septentrional Andina comprende Piura y Tumbes en el Perú, Ecuador y Colombia, cuyas sub-áreas no están aún bien definidas. En Area Central Andina está subdividida de acuerdo a las tres regiones naturales del Perú: Costa, Sierra y Selva y éstas en Norte, Centro y Sur. Nos corresponde a nosotros el estudio de la Sierra Norte.
}

efectuadas durante el XXXVII Congreso Internacional de Americanistas de Buenos Aires y Mar de Plata (1966), los Drs. Betty Meggers y Clifford Evans y John Murra plantearon las bases fundamentales para la realización del citado proyecto. Posteriormente los Dres. Meggers y Evans elaboraron un programa coordinado, en el que expusieron en forma detallada, las necesidades, los fines y los alcances del proyecto, tomando énfasis en el estudio del Período Formativo de la sierra central y de la sierra norte del Perú.

Para los efectos de la investigación, las dos sub-áreas mencionadas se dividieron en 3 zonas. La zona I comprende la cuenca del río Mantaro y está dirigido por Ramiro Matos, con la asistencia de alumnos de la Universidad Nacional del Centro. La zona II comprende la cuenca del Alto Marañón y sus afluente del río Mosna o Pukcha, en el departamento de Ancash y está bajo la dirección del autor del presente informe, con la asistencia de estudiantes y egresados de las universidades San Marcos de Lima y San Agustín de Arequipa. La zona III abarca los departamentos de Cajamarca y Amazonas y está dirigida por Hermilio Rosas y Ruth Shady. 


\section{UBICACIÓN GEOGRÁFICA}

El departamento de Ancash está ubicado entre los $10^{\circ}$ y $9^{\circ}$ de latitud Sur. La zona en estudio comprende el valle interandino del MosnaPukcha, que se halla enclavado entre la variante oriental de la Cordillera Blanca y la vertiente occidental de la Cordillera Oriental, con un recorrido de más de $90 \mathrm{~km}$ hasta su empalme con el valle del Alto Marañón, que recorre de sur a norte. También está comprendido en el programa de estudio la margen izquierda del Alto Marañón en el tramo comprendido entre las provincias del Huari y Antonio Raimondi con una extensión aproximada de $60 \mathrm{~km}$, de los cuales solo han sido explorados 15 . Los niveles de estudio están entre los $2150 \mathrm{msnm}$ (que corresponde a la desembocadura del río Pukcha en el Marañón) y los 4650 msnm (que corresponde a la naciente del río Mosna y sus principales afluentes).

El río Mosna ${ }^{2}$ nace de los nevados de Pongos $(5680 \mathrm{~m})$ Raria $(5590 \mathrm{~m})$ y Huaiyacu (a $5460 \mathrm{~m}$ ), en el flanco occidental de la cordillera Blanca. En su trayecto recibe numerosos afluentes (Tambilla, Chalhuayacu, Yuraj Yacu, Huachecsa, San Marcos, etc). A $30 \mathrm{~km}$ de la desembocadura en el Marañón toma el nombre de Pukcha. El Mosna forma un estrecho valle, casi paralelo al Callejón de Huaylas. Se orienta hacia el Este en Puma Chaca, justamente en el punto que recibe las aguas del Yuraj Yacu o Huari Tambo de Huari.

\section{Ecología}

De acuerdo con el programa del PAEA hemos tratado, en principio, de estudiar la ecología de la zona, empezando por hacer la recolección de plantas de los distintos pisos y comunidades de vegetación, para su análisis e identificación ${ }^{3}$, a fin de contribuir a un mejor conocimiento de

\footnotetext{
2 Todas las cartas geográficas designan con el nombre de Pukcha al valle que nos ocupa. En realidad sólo se llama Pukcha a un pequeño tramo donde se encuentra una hacienda del mismo nombre. La mayor extensión del valle toma el nombre de Mosna. Por esta razón nosotros denominamos en algunos casos, Mosna-Pukcha.
}

3 Las muestras de plantas recolectadas fueron identificadas en el herbario del Museo "Javier Prado" de la Universidad Nacional Mayor de San Marcos. los pisos de vegetación, la distribución de las Unidades Sistemáticas de la zona y, de manera especial, de la ubicación precisa de los pisos transicionales de tensión entre las distintas comunidades conocida con el nombre de ecotonos. Estas fronteras, que son de especial interés ecológico, han sido delimitadas tomando como base que cada comunidad de vegetación origina un ecotono a consecuencia de la lucha con las condiciones físicas o de la competición directa entre ciertas especies. Por ejemplo, la frontera entre una comunidad de arbustos y un pantano, los arbustos pueden competir directamente con la vegetación del pantano por la luz, subsistencias nutritivas u otras necesidades vitales, de tal manera que un tipo de planta cede al otro. En varios sectores del área en estudio las comunidades se entremezclan considerablemente.

El valle es de clima seco y templado, con un régimen de precipitaciones pluviales veraniegas y sequía en el resto de las estaciones y ofrece una marcada diferenciación edáfica, presentando depresiones profundas y estrechos, generalmente arcillosas y pedregosas, y terrenos en pendientes escarpadas constituidas por capas de arenisca metamórfica y metalífera, con notorias vetas de cuarcita aurífera del periodo Silúrico. Cerca al Marañón se observan manchas de terreno cretáceo con equinodermos fósiles que cubren grandes extensiones de arenisca, conjuntamente con calcáreos azulejos con grandes y escasas amonitas deformación Jurásica, y cerca de Chavín y Huari se observan conglomerados porfiríticos y vetas de grano-diorita. Todo esto corresponde al Piso Medio. El piso inferior está formado por arenisca roja, pizarra talcosa y gris. El piso Superior está formado por enormes rocas eruptivas, especialmente pórfido, diorita y granito, y rocas sedimentarias tales como areniscas verdosas y mantos de carbón de piedra.

\section{Pisos De Vegetación}

El escalonamiento fitogeográfico se ha hecho en base a los estudios realizados por Weberbauer $^{4}$, las observaciones hechas por Raimon-

4 Alfred Weberbauer, 1945; especialmente 336-359 y siguientes. 
$\mathrm{di}^{5}$ y a las muestras obtenidas por nosotros. Los principales pisos de vegetación que se describen son los siguientes: 1.- Monte ribereño; 2.Formación de cactáceas columnares y arbustos caducifolios; 3.- Formación de arbustos dispersos más gramíneas; 4.- Monte rígido; 5.- Estepa de gramíneas; y a los que se puede agregar los montes de arroyada, los céspedes de arroyo y asociación de plantas acuáticas que se hallan en distintos niveles.

1.- Manto Ribereño.- Constituido por la vegetación del cauce de los ríos Mosna y marañón, de formación siempre verde y que asciende a niveles más o menos altos (2150 hasta los 2800 $\mathrm{msnm})$. Se caracteriza principalmente por la presencia de plantas de arroyo y de la ribera del valle, formado por arbustos y arbolitos de alturas variables.

Las plantas leñosas alcanzan gran desarrollo a lo largo de las corrientes de agua. Las especies predominantes son el "molle" (Schimus molle), arbusto de corteza agrietada, con flores verdosas y manojos de drupas rojizas; el "huarango" (Acacia macracantha), arbusto espinoso; el "sauce" (Salix humboldtiana); el "haliso" (Agnus jorullensis); árbol cultivado; el "kisuar" (Buddleia incana), de tallo arbóreo entre los arbustos que allí predominan; el "muña" (Minthostachys mollis); varios epifitos, etc. ${ }^{6}$

\section{2.- Formación de cactáceas columnares y ar-} bustos caducifolios. Se extiende desde los 2800 hasta los $3500 \mathrm{~m}$. En este piso el habitat es un tanto árido y seco. Como ejemplos más resaltantes de esta vegetación mencionaremos a la "tara" (Caesalpina spinosa); la "penca" (Agave americana); Pectis ciliares, compuesta pequeña y por cuya abundancia el suelo toma una coloración amarillenta; y diversas variedades de gramíneas.

\section{3.- Formación de arbustos dispersos y gramí-} neas.- Abarca de los 2700 a 3200 m.s.n.m. y presenta plantas de clima templado y de hábitat moderadamente húmedo. Las comunidades están formadas por arbustivas dispersas y

5 Antonio Raimondi, 1873; descripción de la Provincia de Huari.

6 Los nombres de plantas encerrada entre comillas corresponden a los nombres vernaculares (quechua de Ancash). entremezcladas con hierbas perennes y anuales. Entre las especies dominantes citaremos el "Mishue" (Dunalia peruviana), solanácea que soporta largas épocas de sequía y cuyas hojas se mantienen siempre verde dando un aspecto peculiar al ambiente; el "Mucti" (Hesperomeles cuncata) arbusto de hojas cariáceas, y de frutos rojos; el "chunoc" ( Sebastiana obtusifiola), planta temida por el látex caústico que produce, el jugo lechoso que se desprende de la más pequeña herida de esta planta puede causar daño en las mucosas o en la vista; el "Shanqui" (Acana torilicarpa), arbusto de frutos pequeños que se adhieren a la ropa y al cuerpo y al cuerpo de los animales porque tienen unos ganchos e inundan enormes extensiones de terrenos abandonados, el "kara" (Agave americana), de hojas reunidas en roseta en el extremo de un tallo corto y que florecen solamente una vez al final de su ciclo biológico, y es representada en algunas esculturas y cerámica Recuay. Entre las arbustivas que siempre forman montes citaremos al "marco" (Ambrosis peruviana) planta de color grisáceo, utilizada como leña; la "chilca" (Bacharis filoribunda) y otras. Entre las plantas trepadoras epifíticas tenemos a la porocsha" (Passiflora mollisima), planta zarcillosa de flores grandes. En la vegetación rocosa se destacan muy pocas especies: la "congona" (Peperomia sp.) estimada por su valor curativo en casos de traumatismo. La vegetación generalmente herbácea de los campos de cultivo, muchas de ellas malezas o forrajeras : el "rábano" (Brassica camapestris), de hojas estimadas en la alimentación y por cuya floración uniforme los campos toman una coloración amarillenta; la "huetaccora" (Avena Barbata), maleza de rápido desarrollo que crece en manojos compitiendo con las plantas cultivadas. Entre la vegetación de los céspedes de arroyo citaremos al "berro" (Roripa nasturutium-aquaticum), muy apreciado en la alimentación. En este piso hay pocos sitios arqueológicos.

4.- Monte rígido.- Las comunidades de vegetación correspondiente a este piso aparecen a los $3000 \mathrm{~m}$. y ascienden hasta los 3800 m.s.n.m. En esta formación predomina la vegetación arbustiva, caracterizada por la rigidez de sus hojas, especialmente, por cubrirse de resina. Las especies más notables son : Solanum nitidum, cuya resina, hay evidencias, fue empleada por 
los de Recuay para la práctica de la decoración negativa de su cerámica; la "taya" (Lupinus sp.), arbusto que alcanza $4 \mathrm{~m}$ de altura, muy abundante, de hojas compuestas, cubiertas de finos pelos que les dan apariencia aterciopelada, y a la distancia forman manchas de color grisáceo; la "cantuta" (Cantuta buxifolia" que se encuentra en estado silvestre, formando comunidades compactas. Entre la vegetación de ambientes rocosos son frecuentes, la Puya sp., predominante en este hábitat, prefiere lugares inaccesibles; la "huallanca" (Opuntia exaltata), muy abundante en este piso. Entre las especies ruderales, es decir, que crecen cerca de los lugares donde pernoctan los animales domésticos, tenemos al Astragalus gabancillos, lerguminosa de flores azules. La mayor concentración de sitios arqueológicos en varios períodos se hallan en este piso.

5.- Estepa de gramíneas.- A este piso se le designa comúnmente con el nombre de Puna o Territorio Alto Andino ${ }^{7}$, está comprendido entre los $3800 \mathrm{~m}$ y los 4650 m.s.n.m., donde ya no es posible el desarrollo de la agricultura. En este piso predominan las gramíneas que forman pajonales, como el "ichu" (Stipa Ichu y Festuca dolichophylla), gramínea de hojas duras y punzantes. El paisaje de este piso está formado también por oconales, lugares pantanosos de vegetación siempre verde, donde crecen numerosas especies de monotiledóneas y que son lugares de refugio del pastoreo en épocas de sequía. Completa este piso la vegetación de césped de puna, constituido por especies pequeñas casi a ras del suelo, algunas de las cuales forman almohadillados planos o convexos y sirven de alimentos a los auquénidos. La flora de este piso es de gran interés, las especies vegetales manifiestan especiales adaptaciones a las temperaturas bajas y a las fluctuaciones fuertes de temperatura, tales como modificaciones en sus órganos vegetativos (tallos y hojas), los que unas veces están cubiertos de resina y otras veces cubiertos de pelos. Weberbauer nos describe un sitio de puna del área en estudio diciendo que "en los alrededores del lago Querococha, 4,136 $\mathrm{m}^{8}$ situado en las faldas de

7 A. Weberbauer. 1956: p. 366 denomina por primera vez "territorio Alto Andino" a los que generalmente se llama Puna.

8 A. Weberbauer 1945; p. 359 de una información equivocada de la altura de la laguna de Kerocoha que es de $4650 \mathrm{~m}$. la Cordillera Blanca, encima de Recuay, la estepa de gramíneas contiene arbolitos aislados de Escalonia hipsophyla y Buddleia ususch; el tronco de la última, torcido y nudoso, alcanza 4 metros de altura y sostiene una capa tupida de hojas coviáceas y cubiertas de pelos parados en su revés"

\section{REFERENCIAS HISTÓRICAS Y ARQUEOLÓGICAS}

Los datos históricos y arqueológicos son muy escasos, aparte de que las referencias son bastante escuetas en la mayoría de los casos, especialmente las que recogieron los cronistas. Casi todos los que se ocupan de esta zona nos dice que el territorio estuvo ocupado por una nación llamada de los Pinku. Espejo Núñez ha realizado un pequeño estudio al respecto. ${ }^{10}$ El dato más temprano que hemos encontrado hasta el momento, es el de Cieza de León, quien después de describir la provincia de los Conchucos nos habla de las de Piscobamba y Pinkos y dice: "Adelante de esta provincia (Piscobamba) está la de Pincos, cerca de donde pasa un río, en lo cual están padrones para poner la puente que hacen para pasar de una parte a otra. Son los naturales de aquí buenos cuerpos, y que para ser indios tienen gentil presencia". "Hacia 1594, Toribio Alfonso de Mogrovejo, en su Segunda Visita Pastoral, hace una referencia suscinta sobre Pinku, es decir sobre las poblaciones de Huari, Huantar, Chavín, San Marcos y otras. En efecto, dice que en "San Gregorio de Huantar ... tenía este pueblo 162 indios tributarios, 60 reservados, y por todo 576 almas. Tiene por anexo un pueblo que llaman San Pedro de Chavín con 110 tributarios, 30 reservados ,361 de conffisión y 460 ánimas ..." "San Marcos de Collanapincos... con 110 indios tributarios... y 466 almas". ${ }^{12}$ "Nuestra Señora de Guadalupe (actualmente llamado Rapayán) está situado en una ladera, es de buen temple y da el maíz y el trigo". ${ }^{13}$

\section{A. Weberbauer, op. cit.; p. 359.}

10 Espejo Núñez, Julio, 1961. También publica los mismos datos en Cuadernos Americanos, vol. LVI, N1 2, pp. 139-152. Mexico.

11 Cieza de León, 1922; pp. 271-272.

12 Mogrovejo, T. A. de, 1920; pp. 511-512.

13 Mogrovejo, T. A. de, op. cit., p. 416. 
Más adelante dice: "Tiene don Antonio cacique principal del repartimiento de Ucho- pincos, un obraje que está dentro del pueblo de Nuestra Señora, en el cual ocupa hasta veinte indios chicos y grandes". ${ }^{14}$ De esta versión se desprende que la provincia de los Pinku a pocos años de la invasión española estuvo dividida en dos cacicazgos: el de San Marcos de Collanapincos, ubicado en la margen derecha del Mosna, y el de Ucho (Uco)-pincos, cerca de la desembocadura del Mosna-Puchka. Garcilaso de la Vega menciona la existencia de los Pinku y dice: "De allí vinieron los apercibimientos acostumbrados a los naturales de una provincia llamada Pincu, los cuales, viendo que no podían resistir en poder del Inca, y también porque habían sabido cuan bien les iba a todos sus vasallos ... respondieron que holgaban mucho en recibir el Imperio del Inca y sus leyes" "Las (provincias) principales son Huaraz, Piscobamba, Conchucos. Las cuales, habiendo de seguir el ejemplo de Pincu, hicieron lo contrario que se amotinaron". ${ }^{15}$ Antonio Vásquez de Espinoza nos habla sobre la "nación" de los Pinku en varios pasajes de su obra. En su recorrido por el Corregimiento de Conchucos enumera: “... dos religiosos de Santo Domingo en Santo Domingo de Guari, y en Huantar y Chavín, y dos de Nuestra Señora de la Merced en Collanapincos (habitantes de la margen derecha del valle, hoy San Marcos) y hichopincos" (habitantes de la margen izquierda). ${ }^{16}$ Más adelante anota que "...tiene gran distrito la ciudad (de Guanuco) y en el de muchas provincias muy ricas... al norte Guamalíes pincos, Caxatambos, Gocares, Guaylas, Piscobamba, y otras de menor consideración". ${ }^{17}$ También refiere que Pachacutec Inca Yupanqui "conquistó las prouincias de Guamalíes, Pincos, Guare, Piscobamba, Caxatambo, Guaylas, donde quemó algunos sométicos, que auía para que con el castigo se enmendassen y uiesse escarmiento". ${ }^{18}$ Hace referencia sobre un obraje y la existencia de un tambo, ${ }^{19}$ que también es citado por Hua-

14 Mogrovejo, T. A. de, op. cit., pp. 416-417.

15 Garcilaso de la Vega, Inca. 1943; Tomo II.

16 Vásquez de Espinoza, Antonio, 1948; p. 439.

17 Vásquez de Espinoza, Antonio, op. cit., p. 455.

18 Vásquez de Espinoza, Antonio, op. cit., p. 536.

19 Vásquez de Espinoza, Antonio, op. cit., p. 458. mán Poma, quien en forma escueta dice: "Pincos Tambo Real". ${ }^{20}$ Vásquez de Espinoza hace una descripción precisa del río Mosna llamado también Puchka, de las distancias de los poblados de esta zona y de la travesía que se hace de la Cordillera Oriental, "tierra muy fría", para descender al Marañón: "a la mano izquierda un profundo río originado por las nieves, (el Mosna) salido de estas laderas se pasa por el otro río (Marañón) por un puente". ${ }^{21}$ Marco Jiménez de la Espada en un documento fechado en 1649 dice que partiendo de la ciudad de Los Reyes (Lima), "el camino tira por cuestas y serranías altísimas... con las aguas del invierno se hacen ríos como el de Pincos, a quien ciñen dos grandes repechos, y con las vertientes de aquellas sierras se hace río harto provechosa, porque riega los cañaverales que hay en aquella quebrada". ${ }^{22}$ El padre Bernabé Cobo, al narrar la lucha entre Huascar y Atahualpa dice que el capitán Guanca Anqui, partidario de Huascar "dio otra batalla al contrario en Pincos...,y también fue vencido". ${ }^{23}$ Cabello de Balboa al referirse a la huida de los Chancas derrotados por Pachacutec, hace mención a las naciones vecinas y confederadas de los Conchucos; Cabello de Balboa sin citar por su nombre a esta etnía dice que los Chancas "comenzaron a trauar guerras con aquellas naciones confederadas en amistad y vecindad con los Conchucos, y auiende de ellos algunas victorias pasaron a Guamachuco" 24 . Julio C. Tello (26) presenta un "ensayo de reconstrucción de la geografía incaica" y divide el territorio andino en cuatro zonas : en la segunda, que trata sobre las naciones de los Andes del Marañón cita a Pinku en el valle del Mosna-Puchka.

Las informaciones de carácter arqueológico del siglo XIX se circunscriben a cuatro viajeros-científicos que visitaron la zona. (Debo señalar que omito todas las referencias que decenas de autores hacen concretamente sobre el centro ceremonial de Chavín de Huántar, ya que este sitio es objeto de estudio de otro proyecto). En 1830, el sabio arequipeño Ma-

20 Huamán Poma de Ayala, F. 1936, p. 1087.

21 Vásquez de Espinoza, Antonio, op. cit., p. 458.

22 Jiménez de la Espada, Marcos, 1965, Tomo II, p. 14.

23 Cobo, Bernabé, 1964, Tomo II, p. 96.

24 Cabello de Balboa, 1950, pp. 316-317. 
riano Eduardo de Rivero después de describir las truinas de Chavín menciona las ruinas de Posoq (Ms - 2 en nuetra catalogación), y al respecto dice: "A distancia de un cuarto de legua al Oeste del pueblo (de Chavín) y en la cumbre del cerro llamad Posoc (sic) que significa "cosa que se madura", hay otro castillo arruinado que en su exterior no presente sino escombros, pero aseguran que en su interior se encuentran salones" ${ }^{25}$. Hacia Octubre de 1860-61, Antonio Raimondi hace un estudio fitológico, geológico y hace anotaciones de varios sitios arqueológicos ${ }^{26}$. Diez años después de los estudios realizados por Raimondi, el científico alemán E. W. Middendorf, luego de hacer estudios sobre las ruinas de Chavín y sus irradiaciones a la costa, describe la flora del valle del Mosna ${ }^{27}$. Finalmente, Charles Winier, en su monumental obra "Perou et Bolivie" nos presenta descripciones de las ruinas y la cerámica que él encontró en la zona de Chavín y San $\mathrm{Marcos}^{28}$. En la segunda y tercera década del presente siglo, Tello ${ }^{29}$ y Santiago Antúnez de Mayolo $^{30}$ realizaron una serie de estudios en la cuenca del Mosna. Posteriormente Wendel C. Bennett ${ }^{31}$ publica sus estudios de Chavín y del Callejón de Huaylas planteando por primera vez la posición cronológica del estilo Recuay: y, en 1939, Tello da a conocer sus investigaciones mucho más documentadas sobre el valle del Mosna, llamado por él Pukcha ${ }^{32}$. Aparte de todas las referencias anotadas, tanto en el aspecto histórico como en el arqueológico, existen numerosas publicaciones de carácter la obra del Presbítero S. Márquez Zorrilla ${ }^{33}$ que nos trae algunas descripciones de interés geográfico, y el trabajo de Euxodio Ortega ${ }^{34}$ que presenta descripciones de importantes ruinas arqueológicas. Merece especial mención Julio

25 Rivero y Ustáriz, M. Eduardo, 1851, p. 285.

26 Raimondi, Antonio, 1943, vol. II, pp. 127-153.

27 Midendorf, E., 1893-95, Tomo II, pp. 307-315; Tomo II, pp. 93-103.

28 Wiener, Charles, 1885; pp.

29 Tello, Julio C., 1929, cap. III.

30 Antúnez de Mayolo, Santiago 1948, pp. 25-27.

31 Bennett, W. C., 1944.

32 Tello, Julio C., 1942, cap. I y III.

33 Márquez Zorrilla, R. P., 1965, cap I al IV.

34 Ortega, Eudoxio, 1965.
Espejo González, el único que ha presentado interés al estudio y divulgación de la zona que nos ocupa. ${ }^{35}$

\section{Sitios ARQUEOLÓGICOS EXPLORADOS}

Durante la primera etapa de trabajo de campo se han localizado 23 sitios, 17 corresponden al valle de Mosna y los restantes a la margen izquierda del Marañón. De todos ellos se han obtenido muestras sistemáticas de cerámica, artefactos líticos y huesos humanos y de animales, haciendo un total de 6580 fragmentos de cerámica, 15 artefactos líticos, 28 lascas, 85 fragmentos de huesos de animales, 25 huesos humanos y un artefacto de hueso de llama.

\section{Sitio Ms-136: Centro Ceremonial de Chavín de Huántar}

Con el objeto de contar con una muestra estratigráfica, para los efectos de comparación, se ha practicado un corte al sur de las ruinas con muy buenos resultados; obtuvimos una secuencia interesante, siendo el estilo Rocas el más antiguo, en los estratos medios se encontró cerámica perteneciente al estilo Ofrendas y en los estratos superiores aparecieron fragmentos del tipo Blanco/Rojo y Recuay. Esta excavación confirmó en parte la secuencia que teníamos para Chavín, en base a observaciones puramente estilísticas.

\section{Sitio Ms-2: Pogoq}

Anteriormente fue estudiado por Rivero y Ustáriz, en primer lugar, y luego por Tello y Espejo Núñez. Se halla $n$ la cumbre del cerro del mismo nombre, al oeste del pueblo de Chavín, a $3550 \mathrm{~m}$. Para llegar al sitio se asciende por una pendiente muy escarpada de más o menos $55^{\circ}$ de inclinación. Los restos arquitectónicos están destruidos, actualmente solo se observan pequeñas chullpas y terrazas de la época del Es-

\footnotetext{
35 Espejo Núñez, J., 1951, 1957, 1959, 1961.

36 Las siglas Ms corresponden a la abreviatura de Mosna. Más adelante se usa Ma, abreviatura de la cuenca del Marañón.
} 
tado Inca, que son muy aprovechadas para los sembríos periódicos de papas, cebada y trigo. En el flanco occidental se observan numerosas cámaras funerarias y un mausoleo muy deteriorado de la cultura Recuay. Para el muestreo de cerámica el sitio se dividió en ocho sectores de Este a Oeste, con intervalos de $25 \mathrm{~m}$ en consecuencia, Pogoq tiene una extensión de $200 \mathrm{~m}$ de largo. La cerámica muestra una ocupación muy temprana del sitio: se hallaron fragmentos del estilo Rocas, Blanco/Rojo, tiestos utilitarios de la cultura Recuay y un apreciable porcentaje del tipo Inca Provincial.

\section{Sitio Ms-3: Gotush}

Al sur de Chavín, aproximadamente $12 \mathrm{~km}$ en la margen izquierda del Mosna, se levanta un cerro que es uno de los más elevados del valle; en la cumbre que alcanza más de 4000 m están las ruinas de Gotush. Espejo Núñez visitó el sitio en $1941^{37}$. Al igual que Pogoq, los restos de arquitectura se encuentran destruidos, con cierta dificultad se pueden apreciar vestigios de muros circulares y cuadrangulares, a ras del suelo. La muestra de cerámica superficial también atestigua la ocupación de tres épocas: Chavín, Recuay e Inca.

\section{Sitio Ms-4: La banda}

Llamando también Caucho. Se encuentra en el piso inferior del valle, casi en la ribera del Mosna, frente a las ruinas del Chavín. El sitio está cultivado y habitado en la integridad, y esto da la apariencia de que no existe resto arqueológico alguno. Haciendo una exploración detenida se observan restos de cámaras funerarias en forma de cisto y soterrados de típica manufactura Recuay. Se sabe que se han extraído numerosas piezas de cerámica y objetos de metal. Nosotros hemos practicado tres excavaciones, la primera en las inmediaciones de una chacra de maíz y las dos restantes en el interior de un establo. Los tres cortes evidenciaron, como en los casos anteriores, la ocupación Chelín, luego Blanco/Rojo, Recuay y un tipo de cerámica local tardío asociado con el

37 Espejo Núñez, J. op. Cit., estilo Inca; finalmente, se encontró fragmentos de cerámica colonial fabricada con torno.

\section{Sitios Ms-5: Huarijircan}

Es uno de los sitios más importantes. Se encuentra $250 \mathrm{~km}$ al norte del pueblo de Huántar, en la vertiente oriental de la Cordillera Blanca, a $30 \mathrm{~km}$ de Chavín y a $3500 \mathrm{~m}$ de altura. Huarijircan es una colina orientada de Este a Oeste, de 250 × $200 \mathrm{~m}$ aproximadamente. El sector norte remata en una pendiente bastante pronunciada. De Este a Oeste se proyectan dos plataformas superpuestas dando la apariencia de una pirámide truncada. En efecto, tiene las características de un templo de Chavín y reocupado en épocas posteriores. Se observan muy pocas estructuras: las tres cuartas partes del sitio se hallan cultivadas con sembríos de cebada y trigo, lo que no nos permitió hacer un estudio más detenido. Probablemente, el templo ha sido destruido paulatinamente desde la época de la Colonia, tanto por los extirpadores de idolatrías cuanto por los pobladores modernos. El atrio de la torre de la iglesia y los muros de las casas particulares de Huántar están construidos con materiales extraídos de Huarijircan. En vista de que la mayor parte se hallaba cubierto de sembríos no pudimos recolectar restos culturales por el método del muestreo longitudinal por compuestos, sino que procedimos a recoger una muestra sistemática por medio de cuadrículas de $2 \times 2 \mathrm{~m}$ en sitios elegidos al azar. Se recogieron cinco muestras, en las que se distingue fácilmente tipos de cerámica pertenecientes a Chavín (Ofrendas), dos fragmentos probablemente de tipo Kotosh gran porcentaje del tipo Recuay sencillo y decorado, Blanco/Rojo, puntas de pizarra de manufactura Recuay. Fuera de los sectores delimitados se halló una punta de proyectil muy semejante a las halladas por la $\mathrm{Mi}$ sión Japonesa en el sitio de Mito, en Huánuco. En la parte baja de la colina se muestra un enorme corte abierto para prolongar hacia el norte de la calle principal del pueblo de Huántar. La faz oeste de este corte presenta un perfil, donde se puede observar una clara estratificación. En total se observan cinco estratos en dos metros de altura. Una vez más este corte nos muestra una secuencia más completa aún que la anteriores. Primer estrato con cerámi- 
ca Inca y Colonial. Segundo estrato, cerámica estilo local, que estamos llamando Pikos, en la base de este estrato se notan restos de cocina y vestigios de un piso. Tercer estrato, relleno de piedras, sin contenido arqueológico. Cuarto estrato: con varios lentes de ceniza: con contenido de cerámica Recuay y pequeña cantidad de tiestos Huaraz Blanco/Rojo. Quinto estrato, cerámica Huaraz Blanco/Rojo asociado con restos Chavín.

\section{Sitio Ms-6: Piruroyoc}

Ubicado a $300 \mathrm{~m}$ al sur de Huarijircan en Huántar. Tiene todas las características de un adoratorio de planta circular de $20 \mathrm{~m}$ de diámetro, con un pequeño vano de acceso de 70 $\mathrm{cm}$ de ancho. El muro circular de un metro de ancho está constituido con grandes bloques de rocas canteadas unidas con argamasa de barro. Por su forma circular (piruro = circular) los moradores lo han aprovechado para otros fines, especialmente para la trilla de cebada. Hemos recuperado pequeño cantidad de cerámica perteneciente al Periodo del Desarrollo regional y lascas de cuarcita y obsidiana.

\section{Sitio Ms-17: Gotush Punta}

En 1941 fue localizado por Espejo Núñez y marino Gonzáles ${ }^{38}$ quienes lo bautizaron con el nombre de Picudo. Gotush Punta se halla a $18 \mathrm{~km}$ al sur de Chavín, en la margen izquierda del Mosna. Los restos arquitectónicos han sido destruidos, de los seis muros concéntricos que Espejo Núñez describió en su visita de 1941 solo quedan pequeños vestigios. La mayor parte del sitio, que abarca $400 \mathrm{~m}$ de largo, se halla cultivada. La cerámica superficial es bastante escasa; la pequeña muestra atestigua ocupación Chavín, Recuay y de un estilo local tardío (Pinkos).

Sitio Ms-8: Wuaman Wain I; Ms-9: Wuaman Wain II; Wuaman Wain III (Wuaman Wain $=$ Casa del Halcón)

Los tres sitios citados constituyen un mismo conjunto arqueológico. Por razones de trabajo y por las distancias que existen entre uno y

38 Espejo Núñez, J., 1957, pp. 137-150. otro sitio, lo hemos dividido en tres. Wuaman Wain I se halla a pocos metros de la margen derecha del Mosna y sólo presenta pequeñas estructuras de paredes y una reducida cantidad de cerámica superficial. Ascendiendo hacia el este nos encontramos con Wuaman Wain II, donde se aprecian piedras labradas con corte tipo Chavín, ahora agrupadas con fines religiosos modernos. Wuaman Wain III es el más importante, se halla a $5 \mathrm{~km}$ en pendiente del pueblo de Chavín y a $300 \mathrm{~m}$ sobre el nivel del Mosna. Limita por el norte con un barranco profundo cortado casi verticalmente; por el sur con una quebrada de pendiente suave por donde corre un riachuelo; por el Este con cerros escarpados que rematan en picos con manchas de morrenas que sobrepasan los 4000 $m$ de altitud. En Wuaman Wain III, se aprecian plataformas superpuestas de muros de engaste que sirven de contención de terrazas; edificios funerarios cuadrangulares de mampostería ordinaria, irregular y concentrada, con cimientos de poca profundidad. Estos edificios semidestruidos se hallan dispersos encima de las terrazas y han sido profanados casi en su totalidad; restos de muros de mampostería seca, o sea sin argamasa, los componentes son piedras ligeramente canteadas y mezcladas con piedras pulidas de estilo Chavín. Los muros en referencia son construcciones post Chavín y a juzgar por la disposición de la hiladas y manpuestos han sido reconstruidos en distintas épocas, muros construidos con piedras labradas en forma de paralelepípedo y hechas de pórfido y granodiorita, son típicos de la época Chavín. Los restos de cerámica nos indican que Wuaman Wain III ha estado ocupado por chavinenses de la primera época. La mayor cantidad de tiestos decorados son del periodo Rocas (1150 a.C.). Espejo Núñez ${ }^{39}$ nos muestra dibujos de tiestos de estilo idéntico al Rocas extraídos de la galería del mismo nombre en el centro ceremonial de Chavín. El mismo autor da noticias de haber encontrado un fragmento de lápida ${ }^{40}$ hecha de grano-diorita, los motivos y disposición de la decoración que muestra el fragmento de la lápida son del periodo Ofrendas de Chavín. Tenemos programado para Julio de 1971 realizar excavaciones intensivas en el sitio.

39 Espejo Núñez, J., 1961, pp. 115-128.

40 Espejo Núñez, J., 1951, p. 147, fig. 4. 


\section{Sitio Ms-11: Cueva Pintada}

Durante la primera etapa de exploración localizamos varias cuevas y abrigos rocosos en la vertiente oriental de la Cordillera Blanca, lo mismo que en la quebrada de Pukcha, pero nuestro interés se orientó en el estudio de la cueva en referencia por su ubicación muy estratégica $(4350 \mathrm{~m})$ de donde se domina todo el valle de Pukcha y sobre todo porque su interior está pintado de rojo. El material que forma la cueva es un conglomerado de caliza en proceso de desintegración. Los desprendimientos del techo habían dejado enormes huecos que fueron rellenados con barro y pintado asimismo de rojo. Incluso se pudo analizar los terrones pintados, encontrándose que fueron pintados en tres ocasiones. Pero desafortunadamente cuando realizamos la excavación en el interior de la cueva (que tiene $6 \mathrm{~m}$ de profundidad), no encontramos ningún resto de interés arqueológico. La basura extraída de los tres estratos es moderna. En el estrato IV encontramos rostros humanos cubiertos con tela de manufactura moderna. El estrato $\mathrm{V}$ es totalmente estéril y forma propiamente el piso de la cueva.

Sitio Ms-12: Olayán I y Sitio Ms-13: Olayán II

Se hallan a $20 \mathrm{~km}$ al norte de Chavín, en el distrito de Huántar, margen izquierda del Mosna. Olayán I es importante por la abundancia de fragmentería de cerámica y las de cuarzo y pizarrosa. A simple vista los tiestos pertenecen a periodos tempranos del Desarrollo regional. En tanto que Olayán II consiste en un cementerio de la cultura Recuay, caracterizado por la presencia de las tumbas soterradas con varios compartimientos y hornacinas para el depósito de ofrendas; lamentablemente todas las tumbas que hemos inspeccionado se hallan excavadas. En la superficie hay un $80 \%$ de cerámica utilitaria Recuay y algunos fragmentos decorados de Blanco/Rojo Huaraz.

\section{Sitio Ms-14: Warayoc}

En lo referente a la abundancia y conservación de restos arquitectónicos, Warayoc es el sitio más importante de la cuenca del Mosna. Está ubicado a $4200 \mathrm{~m}$ al suroeste de Chavín, en pleno territorio Alto Andino. Constituye una aldea aglutinada de la época Inca Imperial. El conjunto de habitaciones de planta rectangular, muros de protección, chullpas funerarias, etc. se hallan en buen estado de conservación. Probablemente, estuvo ocupado durante los primeros decenios de la Colonia. Los restos de la cerámica atestiguan la ocupación de dos épocas sucesivas: Reinos y Confederaciones e Inca.

Los sitios Ms-15, Ms-16 y Ms-17, que corresponden a Pitej, Wauya Punku Y Kalli Pataj, respectivamente, son de relativa importancia; los restos arquitectónicos son muy escasos y la pequeña cantidad de cerámica recuperada (pertenece a) pertenece a periodos tardíos. Los tres sitios son utilizados actualmente como terrenos de sembrío.

\section{Sitio Ma-1: Rapayán}

Por razones prácticas, el complejo de ruinas que se encuentra en el filón del cerro Rapayán lo hemos dividido en 6 barrios, con nombre propios. El complejo Rapayán (tenemos un informe detallado aparte) se encuentra en la margen izquierda del Alto Marañón a 90 km de Chavín, en el distrito de Rapayán ${ }^{41}$ de la provincia de Huari. Pertenece a la gran cadena de monumentos situados en ambas márgenes del Alto Marañón, que empiezan a extenderse desde el nacimiento del citado río hasta las provincias de Pataz y San Martín donde se encuentran las ruinas de Pajatén y más al norte, conformando siempre esta cadena, remata con las fabulosas ruinas de Cuelap. Tanto Rapayán como sus similares Tantamayo, Chavinillo, estudiados por Flornoy ${ }^{42}$, Ichu, perteneciente a un sub-grupo de los Chupachos ${ }^{43}$ y muchos otros aún no estudiados, constituyen una sola unidad cultural y geográfica. Las decenas de sitios estudiados por los citados arqueólogos y los seis del complejo de Rapayán presentan las siguientes característica en común: a) Están emplazadas en la cumbre de colinas y cerros

41 El pueblo de Rapayán fue creado por Ley № 11862, de 12 de setiembre de 1952. Antes de la dación de la ley conservaba el nombre colonial de Nuestra Señora de Guadalupe.

42 Flornoy, Bertrand, 1955-56, 1961.

43 Thompson, D., 1967, pp. 356-363. 
elevados, probablemente con fines defensivos y/o las partes bajas eran aprovechadas para la agricultura; b) Todos muestran edificios de 4, 6 u 8 pisos construidos con piedras pequeñas y unidas con argamasa compuesta de arcilla y cuarzo molido, que da gran consistencia; c) A intervalos regulares se erigieron enormes torreones de planta circular, semicircular y en muy pocos casos pentagonal, como especie de miradores; d) Las viviendas de planta irregular, en muy contados casos cuadrangular, que fueron utilizadas por personajes de importancia ubicados de preferencia en las partes elevadas, son muy angostas y alargadas debido al empleo de la técnica imperfecta de la falsa bóveda, también llamada bóveda de hiladas horizontales. La técnica consiste en el empleo de hiladas que se apoyan horizontalmente, proyectando cada vez más hasta cubrir el espacio que debe cerrarse. Las hiladas se sostienen porque cada una de éstas tiene mayor longitud en la parte que está cubierta dentro del muro que en la que se proyecta hacia el exterior. Otra característica resaltante es el empleo del clavete, con una o dos ventanas pequeñas de forma trapezoidal; e) La existencia de mausoleos de dos o tres pisos, en los que se efectuaban enterramientos colectivos; f) Presencia de murallas muy altas con fines defensivos y divisorios; $g$ ) Enterramientos colectivos en grutas o abrigos rocosos en pendientes casi inaccesibles, donde los inhumados momificados se hallan en perfecto estado de conservación; h) Cerámica de tipo estampado y con decoraciones escultóricas burda en apliqué del periodo Reinos y Confederaciones; y, i) Cerámica Inca Imperial y Provincial. Por la unidad cultural de esta extensa zona, postulamos que pertenecen a un mismo momento histórico que tentativamente pondríamos llamar "Cultura de Alto Marañón".

En un pequeño corte practicado en el Sector I de Rapayán (Uchku Rajá) hemos podido obtener una secuencia que parte con Chavín en el nivel inferior (aún no concluido). El estrato inmediatamente superior nos da la presencia del estilo infalible Blanco/Rojo Huaraz, que indudablemente forma un gran horizonte en la costa central y norte y en la sierra norte hasta el Ecuador donde se le llama estilo Tejar. Encima de este estrato se halla una cerámica local y luego la cerámica también local del Complejo Rapayán, y finalmente pocos fragmentos Inca Provincial. Las muestras sistemáticas de superficie y de las excavaciones se hallan en proceso de análisis.

En conclusión, durante la primera etapa de exploraciones, se han obtenido resultados satisfactorios. Sabemos que de los 24 sitios, que incluye uno situado en el mismo pueblo de Chavín y que no se halla graficado en el mapa, 10 tienen restos del Formativo y uno probablemente pertenezca también al Arcaico Superior. Excavaciones futuras que tenemos proyectadas para 1970 y exploraciones más intensivas en el Alto Marañón, nos darán mayores luces para resolver los problemas aún confusos sobre el desarrollo del Formativo y periodo inmediatamente anteriores de esta zona.

\section{Bibliografía}

ANTUNEZ DE MAYOLO, Santiago.- "Por las tierras de Huari. Segunda Parte: los animales totémicos del Valle de Puccha". En El Comercio, Lima, 12 y 13 de julio. 1920.

BENNET, Wendell C.- "The North Highlands of Peru, excavations in the Callejon de Huaylas and at Chavin de Huantar". Vol 39, part 1, Anthropological papers of the American Museum of Natural History. New York. 1944.

CABELLO DE VALBOA, Miguel.- Miscelánea Antártica. Una historia del Perú Antiguo. UNMSM, Facultad de Letras, Instituto de Etnografía, Lima. 1951.

CIEZA DE LEÓN, Pedro.- La Crónica del Perú. Espasa Calpe editores. Barcelona, España. 1922.

COBO, Bernabé.- Historia del Nuevo Mundo. Biblioteca de autores españoles. Tomo II, Madrid. 1964.

ESPEJO NÚÑEZ, Julio.- "Exploraciones arqueológicas en las cabeceras del Puchka (Perú)". En Cuadernos Americanos. Año X, Vol. LVI, pp. 139-152. México. 1951.

ESPEJO NÚÑEZ, Julio.- "Primeros indicios arqueológicos del estilo cultural Huaylas (Re- 
cuay) en la cuenca del Pukcha (Perú)". En Cuadernos Americanos, año XVI, Vol. VIII, XCI № 1, pp. 137-150, México. 1957.

ESPEJO NÚÑ̃Z, Julio.- "Katayok y MolleUkru. Perú Indígena. Órgano del Instituto Indigenista Peruano, vol. VIII. № 18, 54 pp. 91 98, Lima. 1959.

FLORNOY, Bertrand. - "Exploration archéologique de l'Alto Marañón (dessources du Marañón au Rio Sarma)". Travaux. Institut Francaise d'Estudes Andines. Vol. V. Lima, París. 1955-56.

FLORNOY, Bertrand.- "Monumentos de la región de Tantamayo". Journal de la Societé des Américanistes. Tomo XLVI. Nouville serie. París. 1957.

GARCILASO DE LA VEGA, Inca.- Comentarios Reales de los Incas. Emecé Editores. Tomo II, Buenos Aires. 1943.

HUAMÁN POMA DE AYALA, Felipe.- El Primer Nueva Crónica y Buen Gobierno. París. Ed. Paul Rivet. 1936.

JIMÉNEZ DE LA ESPADA, Marcos.- Relaciones Geográficas de Indias, Perú. Tomo II. Biblioteca de autores españoles. Tomo CLXXXVI, Madrid. 1965.

MARQUEZ ZORRILLA, Santiago (Pbro.).Huari y Conchucos. Monografía, segunda edición. Lima. 1965.

MIDDENDORF, E. W.- Perú. Tomo II y Tomo III. Berlín. 1893-95.

MOGROVEJO, Toribio Alfonso de.- "Libro de Visitas 1593 (sic) Diario de la Segunda visita Pastoral, que hizo a su Arquidiócesis el ilustrísimo señor Dn. T. A. de M., Arzobispo de Los
Reyes". Revista del Archivo Nacional del Perú. Entrega III, p. 412, Lima. 1922.

ORTEGA, Eudoxio H.- Los Konchucos. Librería e Imprenta D. Miranda. Lima. 1956.

RAIMONDI, Antonio.- El Departamento de Ancash y sus riquezas minerales. Imprenta de El Nacional. Lima. 1863.

RAIMONDI, Antonio.- Notas de Viajes para su obra "El Perú". (Viaje al departamento de Ancash 1860-61). Lima. 1943.

RIVERO, Marano E. y Juan Diego de TSCHUDI.- Antiguedades Peruanas. Imprenta Imperial de la Corte y del Estado. Viena. 1851.

TELLO, Julio C.- Antiguo Perú. Primera Época. Editado por la Comisión del II Congreso Sudamericano de Turismo. Lima. 1929.

TELLO, Julio C.- "Origen y Desarrollo de las Civilizaciones Prehistóricas Andinas". En Actas y Trabajos Científicos del XXVII Congreso Internacional de Americanistas, Lima. 1942.

THOMPSON, Donald E.- "Investigaciones arqueológicas en las aldeas Chupachu de Ichu y Auquimarca". En Visita de la Prouncia de Huánuco en 1562. pp. 359-362. Huánuco. 1967.

VÁSQUEZ DE ESPINOZA, Antonio.- Compendio y descripción de las indias occidentales. Smithsonian Miscellaneous Collections. Vol. 108, Washington. 1948.

WEBERBAUER, Augusto.- El mundo vegetal de los andes peruanos. Estudio fitogeográfico. Ed. Lumen. Lima. 1945.

WIENER, Charles.- Pérou et Bolivie. París. 1830 . 